\title{
Obesity associated with increased postoperative pulmonary complications and mortality after trauma laparotomy
}

\author{
Jose Covarrubias $^{1}$ (D) Areg Grigorian ${ }^{1} \cdot$ Sebastian Schubl ${ }^{1} \cdot$ Sahil Gambhir $^{1} \cdot$ Matthew Dolich $^{1} \cdot$ Michael Lekawa $^{1}$. \\ Ninh Nguyen ${ }^{1} \cdot$ Jeffry Nahmias ${ }^{1}$
}

Received: 20 November 2019 / Accepted: 11 February 2020 / Published online: 22 February 2020

○) Springer-Verlag GmbH Germany, part of Springer Nature 2020

\begin{abstract}
Background Patient-related risk factors for the development of postoperative pulmonary complications (PPCs) include age $\geq 60$-years, congestive heart failure, hypoalbuminemia and smoking. The effect of obesity is unclear and has not been shown to independently increase the likelihood of PPCs in trauma patients undergoing trauma laparotomy. We hypothesized the likelihood of mortality and PPCs would increase as body mass index (BMI) increases in trauma patients undergoing trauma laparotomy.

Methods The Trauma Quality Improvement Program (2010-2016) was queried to identify trauma patients $\geq 18$-years-old undergoing trauma laparotomy within 6-h of presentation. A multivariable logistic regression analysis was used to determine the likelihood of PPCs and mortality when stratified by BMI.

Results From 8,330 patients, 2,810 (33.7\%) were overweight (25-29.9 kg/m²), $1444(17.3 \%)$ obese $\left(30-34.9 \mathrm{~kg} / \mathrm{m}^{2}\right), 580$ $(7.0 \%)$ severely obese $\left(35-39.9 \mathrm{~kg} / \mathrm{m}^{2}\right)$, and $401(4.8 \%)$ morbidly obese $\left(\geq 40 \mathrm{~kg} / \mathrm{m}^{2}\right)$. After adjusting for covariates including age, injury severity score, chronic obstructive pulmonary disease, smoking, and rib/lung injury, the likelihood of PPCs increased with increasing BMI: overweight $(\mathrm{OR}=1.37$, CI 1.07-1.74, $p=0.012)$, obese (OR = 1.44, CI 1.08-1.92, $p=0.014)$, severely obese $(\mathrm{OR}=2.20$, CI 1.55-3.14, $p<0.001)$, morbidly obese $(\mathrm{OR}=2.42$, CI 1.67-3.51, $p<0.001)$, compared to those with normal BMI. In addition, the adjusted likelihood of mortality increased for the morbidly obese (OR =2.60, CI 1.78-3.80, $p<0.001)$ compared to those with normal BMI.

Conclusion Obese trauma patients undergoing emergent trauma laparotomy have a high likelihood for both PPCs and mortality, with morbidly obese trauma patients having the highest likelihood for both. This suggests obesity should be accounted for in risk prediction models of trauma patients undergoing laparotomy.
\end{abstract}

Keywords Obesity $\cdot$ Trauma $\cdot$ Laparotomy $\cdot$ Mortality $\cdot$ Pulmonary $\cdot$ Complications

\section{Introduction}

Obesity has become a national epidemic within the United States that continues to rise at an alarming rate. According to the Center for Disease Control and Prevention, the

Electronic supplementary material The online version of this article (https://doi.org/10.1007/s00068-020-01329-w) contains supplementary material, which is available to authorized users.

Jose Covarrubias

jcovarrubias008@gmail.com

1 Division of Trauma, Burns, Surgical Critical Care and Acute Care Surgery, Department of Surgery, University of California, Irvine Medical Center, 333 The City Blvd West, Suite 1600, Orange, CA 92868-3298, USA prevalence of obesity in the United States reached nearly $40 \%$ among adults or over 93 million people in 2015-2016 [1]. Although the relationship between obesity and chronic illness is well studied and understood [2-7], its relationship with acute illness and immediate post-trauma surgical complications is less clear. Given the rising prevalence of obesity, it is far more likely now that a significant proportion of the trauma population will be composed of individuals with an obese body mass index (BMI). To optimize care for obese trauma patients, particularly in those requiring surgical intervention, we must continue to enhance our understanding of obesity and its impact on outcomes in trauma.

To date, several studies have been conducted to investigate this relationship, but the results are inconsistent. Some studies suggest obesity may be an independent risk factor 
for poor outcomes in trauma [8-15] whereas others have not demonstrated any such association [16-23]. However, a meta-analysis of these studies with nearly 7800 obese trauma patients found an association between obesity and higher risk of mortality and in-hospital complications such as acute respiratory distress syndrome (ARDS) [24]. Recent studies have observed a higher risk of mortality and in-hospital complications among severely obese and morbidly obese trauma patients $[25,26]$, suggesting outcomes in trauma may vary depending on the degree of obesity. While there have been multiple studies on general surgical populations purporting the increased risk for postoperative pulmonary complications (PPCs) and mortality with a laparotomy as well as with obesity independently [16, 27-29], fewer studies have specifically examined the association of obese trauma patients requiring trauma laparotomy. Furthermore, obesity is not currently considered among the patient-related risk factors for the development of PPCs [30]. One of the few available studies is a single-center study by Livingston et al. in which obesity was not shown to be associated with increased morbidity and mortality following trauma laparotomy [31]. However, higher rates of in-hospital complications such as pneumonia have been reported in obese trauma patients undergoing damage control laparotomy (DCL) [32] with higher mortality rates reported among the morbidly obese [33].

Therefore, we sought to evaluate how obesity impacts PPCs and mortality, hypothesizing the likelihood of mortality and PPCs including ventilator-associated pneumonia (VAP), pneumonia, and ARDS would increase as BMI increased in adult trauma patients undergoing trauma laparotomy.

\section{Methods}

This study was approved by the institutional review board at our institution. A retrospective analysis of the Trauma Quality Improvement Program (TQIP) was performed between January 2010 and December 2016. All trauma patients $\geq 18$ years of age undergoing trauma laparotomy within 6-h of presentation with documented height and weight were included. Those with an abbreviated injury scale (AIS) of the thorax $>2$ were excluded from the study to prevent significant thoracic injury from confounding the analysis on PPCs.

Demographic variables collected included age, gender, race and comorbidities. The injury profile included injury severity score (ISS), mechanism of injury, and injury types. All variables were coded as present or absent. Descriptive statistics were performed for all variables and stratified by BMI according to the World Health Organization guidelines: normal $\left(18.50-24.9 \mathrm{~kg} / \mathrm{m}^{2}\right)$, overweight $\left(25-29.9 \mathrm{~kg} / \mathrm{m}^{2}\right.$ ), obese $\left(30-34.9 \mathrm{~kg} / \mathrm{m}^{2}\right)$, severely obese $\left(35-39.9 \mathrm{~kg} / \mathrm{m}^{2}\right)$, and morbidly obese $\left(\geq 40 \mathrm{~kg} / \mathrm{m}^{2}\right)$ [34]. Trauma patients with overweight, obese, severely obese and morbidly obese BMI were each compared to a reference group of trauma patients with a normal BMI. A one-way ANOVA test was used along with a post-hoc tukey analysis to compare the overweight, obese, severely obese, and morbidly obese groups to patients with normal BMI. Categorical data were reported as percentages, and continuous data were reported as medians with interquartile range. The primary outcome was in-hospital mortality. The secondary outcomes were PPCs including VAP, pneumonia, or ARDS. Other measured outcomes included total hospital length of stay (LOS), intensive care unit (ICU) LOS, days spent on a ventilator, and other postoperative in-hospital complications.

The magnitude of the association between predictor variables and PPCs or mortality was measured using a univariable logistic regression model and chosen based on a review of the literature [30, 35-37]. Covariates chosen included systolic blood pressure (SBP) $\leq 90 \mathrm{mmHg}$ within 24-h, age $\geq 65$-years-old, ISS $\geq 25$, massive blood product transfusion ( $\geq 6$ units of packed red blood cells within 4-h), rib injury, lung injury, severe (grade $>3$ ) AIS for the head, spine, and abdomen, as well as history of peripheral vascular disease (PVD), end-stage renal disease (ESRD), diabetes, hypertension, smoking, chronic obstructive pulmonary disease (COPD) and cerebrovascular accident (CVA). Covariates with statistical significance $(p<0.20)$ were included in a hierarchical multivariable logistic regression model and the adjusted likelihood for PPCs or mortality were reported with an odds ratio (OR) and 95\% confidence intervals (CI) after stratification by BMI. The reference group used in our analysis included all adult trauma patients with normal BMI undergoing trauma laparotomy within $6 \mathrm{~h}$ of presentation. All p-values were two-sided, with a statistical significance level of $<0.05$. All analyses were performed with IBM SPSS Statistics for Windows (Version 24, IBM Corp., Armonk, NY).

\section{Results}

\section{Demographics of adult trauma patients undergoing trauma laparotomy stratified by BMI}

A total of 8,330 patients underwent trauma laparotomy within 6-h. Of these patients, $3095(37.2 \%)$ were normal weight, $2810(33.7 \%)$ were overweight, 1444 (17.3\%) were obese, 580 (7.0\%) were severely obese, and $401(4.8 \%)$ were morbidly obese. In relation to patients with normal BMI, overweight, obese, severely obese, and morbidly obese patients had a higher median age $(32,35,35$ and 34 vs 27 -years-old) with obese and severely obese patients having 
a similar percentage of males ( $81.2 \%$ and $79.2 \%$ vs $80.2 \%)$, overweight patients having a higher percentage $(84.0 \%$ vs $80.2 \%$ ) and morbidly obese patients having a lower percentage (71.8\% vs $80.2 \%)$. Other patient demographics are available in Table 1.

The most common mechanism of injury was gunshot wound across all four groups followed by motor vehicle collision and stab-wound. The most common injury type across all four groups was injury to the small intestine followed by colorectal injury. In relation to patients with normal BMI, overweight, obese, and morbidly obese patients had more rib injuries $(8.8 \%, 8.7 \%$, and $12.0 \%$ vs $5.9 \%$ ) (Table 2).

\section{Clinical outcomes in adult trauma patients undergoing trauma laparotomy stratified by BMI}

Compared to patients with normal BMI, overweight, obese, severely obese, and morbidly obese patients had a longer LOS (8.0, 9.0, 9.0 and 10.0 vs 8.0), ICU LOS (4.0, 4.0, 5.0 and 5.0 vs 3.0 ), and median ventilator days (3.0, 3.0, 3.0 and 4.0 vs 2.0 ). The rate of pneumonia was higher in overweight, severely obese, and morbidly obese patients relative to patients with normal BMI $(4.9 \%, 7.1 \%$ and $8.5 \%$ vs $3.2 \%$ ). There was no difference in the rate of VAP among all patient groups whereas the rate of ARDS was higher for morbidly obese patients ( $5.2 \%$ vs $1.0 \%)$. Relative to patients with normal BMI, the mortality rate was found to be higher only in morbidly obese patients (13.2\% vs $5.1 \%$ ) (Table 3 ).

\section{Likelihood of PPCs and mortality in adult trauma patients undergoing laparotomy stratified by BMI}

After adjusting for covariates in a multivariable logistic regression model, the likelihood of pneumonia increased in overweight $(\mathrm{OR}=1.40$, CI 1.07-1.84, $p=0.013)$, severely obese $(\mathrm{OR}=2.25$, CI $1.52-3.31, p<0.001)$, and morbidly obese patients (OR $=2.12$, CI 1.39-3.24, $p=0.001$ ). The likelihood of VAP increased in obese patients $(\mathrm{OR}=3.17$, CI 1.01-9.97, $p=0.048)$ and the likelihood of ARDS increased in morbidly obese patients $(\mathrm{OR}=4.85$, CI 2.72-8.65, $p<0.001$ ) (Table 4). Altogether, the adjusted likelihood of developing PPCs increased with increasing BMI: overweight ( $\mathrm{OR}=1.37$, CI 1.07-1.74, $p=0.012$ ), obese (OR $=1.44$, CI $1.08-1.92, p=0.014)$, severely obese

Table 1 Demographics of adult trauma patients undergoing trauma laparotomy stratified by body mass index

\begin{tabular}{|c|c|c|c|c|c|}
\hline Characteristic & $\operatorname{Normal}^{\mathrm{a}}(n=3095)$ & Overweight $(n=2810)$ & Obese $(n=1444)$ & Severely obese $(n=580)$ & Morbidly obese $(n=401)$ \\
\hline Age, year, median (IQR) & $27.0(18)$ & $32.0(21)^{\mathbf{b}}$ & $35.0(21)^{\mathrm{b}}$ & $35.0(22)^{b}$ & $34.0(20)^{b}$ \\
\hline Sex, male, $n(\%)$ & $2482(80.2 \%)$ & $2358(84.0 \%)^{\mathrm{b}}$ & $1172(81.2 \%)$ & $458(79.2 \%)$ & $288(71.8 \%)^{\mathrm{b}}$ \\
\hline \multicolumn{6}{|l|}{ Race, $n(\%)$} \\
\hline White & $1328(42.9 \%)$ & $1287(45.8 \%)$ & $709(49.1 \%)^{\mathrm{b}}$ & $286(49.3 \%)^{\mathrm{b}}$ & $204(50.9 \%)^{\mathrm{b}}$ \\
\hline Black & $1308(42.3 \%)$ & $1031(36.7 \%)^{b}$ & $508(35.2 \%)^{\mathrm{b}}$ & $204(35.2 \%)^{\mathrm{b}}$ & $145(36.2 \%)^{\mathrm{b}}$ \\
\hline Hispanic & $365(11.8 \%)$ & $453(16.1 \%)^{\mathrm{b}}$ & $213(14.8 \%)^{\mathrm{b}}$ & $81(14.0 \%)$ & $58(15.7 \%)$ \\
\hline Asian & $81(2.6 \%)$ & $48(1.7 \%)^{\mathrm{b}}$ & $19(1.3 \%)^{\mathrm{b}}$ & $4(0.7 \%)^{b}$ & $2(1.0 \%)^{\mathrm{b}}$ \\
\hline ISS, median (IQR) & $14.0(10)$ & $14.0(11)$ & $14.0(10)$ & $14.0(9)$ & $16.0(14)^{\mathrm{b}}$ \\
\hline SBP, median (IQR) & $122.0(34)$ & $123.0(38)$ & $126.0(37)^{\mathrm{b}}$ & $125.0(38)$ & $122.0(42)$ \\
\hline HR, median (IQR) & $93.0(28)$ & $93.0(30)$ & $96.0(31)^{b}$ & $99.0(32)^{\mathrm{b}}$ & $103.5(33)^{\mathrm{b}}$ \\
\hline GCS, median (IQR) & $15(0)$ & $15(0)$ & $15(0)$ & $15(1)$ & $15(0)$ \\
\hline EtOH Screen Positive & $816(26.3 \%)$ & $795(28.3 \%)$ & $373(25.8 \%)$ & $137(23.6 \%)$ & $76(19.0 \%)^{b}$ \\
\hline $\begin{array}{l}\text { Drug Screen Positive } \\
\text { Comorbidities, } n(\%)\end{array}$ & $830(26.8 \%)$ & $690(24.6 \%)$ & $323(22.3 \%)^{\mathrm{b}}$ & $145(25.0 \%)$ & $90(22.4 \%)$ \\
\hline Hypertension & $215(6.9 \%)$ & $315(11.2 \%)^{\mathrm{b}}$ & $256(17.7 \%)^{\mathrm{b}}$ & $121(20.9 \%)^{b}$ & $104(25.9 \%)^{\mathrm{b}}$ \\
\hline Diabetes Mellitus & $81(2.6 \%)$ & $109(3.9 \%)$ & $99(6.9 \%)^{\mathrm{b}}$ & $51(8.8 \%)^{\mathrm{b}}$ & $51(12.7 \%)^{\mathrm{b}}$ \\
\hline $\mathrm{CHF}$ & $9(0.3 \%)$ & $20(0.7 \%)$ & $8(0.6 \%)$ & $3(0.5 \%)$ & $10(2.5 \%)^{\mathrm{b}}$ \\
\hline CVA & $9(0.3 \%)$ & $13(0.5 \%)$ & $9(0.6 \%)$ & $4(0.7 \%)$ & $0(0.0 \%)$ \\
\hline COPD & $109(3.5 \%)$ & $109(3.9 \%)$ & $49(3.4 \%)$ & $30(5.2 \%)$ & $34(8.5 \%)^{b}$ \\
\hline Cirrhosis & $27(0.9 \%)$ & $29(1.0 \%)$ & $14(1.0 \%)$ & $6(1.0 \%)$ & $6(1.5 \%)$ \\
\hline CKD & $5(0.2 \%)$ & $10(0.4 \%)$ & $8(0.6 \%)$ & $3(0.5 \%)$ & $4(1.0 \%)$ \\
\hline Smoker & $967(31.2 \%)$ & $760(27.0 \%)^{\mathrm{b}}$ & $330(22.9 \%)^{\mathrm{b}}$ & $140(24.1 \%)^{\mathrm{b}}$ & $101(25.2 \%)$ \\
\hline
\end{tabular}

$I Q R$ interquartile range, ISS injury severity score, $S B P$ systolic blood pressure, $H R$ heart rate, GCS Glasgow coma scale, $E t O H$ alcohol, $C H F$ congestive heart failure, $C V A$ cerebrovascular accident, $C O P D$ chronic obstructive pulmonary disease, $C K D$ chronic kidney disease

${ }^{a}$ Reference group

${ }^{\mathbf{b}}$ Statistically significant 
Table 2 Mechanism and injuries of adult trauma patients undergoing trauma laparotomy stratified by body mass index

\begin{tabular}{|c|c|c|c|c|c|}
\hline Characteristic & $\operatorname{Normal}^{\mathrm{a}}(n=3095)$ & Overweight $(n=2810)$ & Obese $(n=1444)$ & Severely obese $(n=580)$ & $\begin{array}{l}\text { Morbidly } \\
\text { obese } \\
(n=401)\end{array}$ \\
\hline \multicolumn{6}{|l|}{ Mechanism, $n(\%)$} \\
\hline MVC & $573(18.5 \%)$ & $539(19.2 \%)$ & $295(20.4 \%)$ & $123(21.2 \%)$ & $82(20.4 \%)$ \\
\hline MCC & $68(2.2 \%)$ & $97(3.5 \%)$ & $65(4.5 \%)^{\mathrm{b}}$ & $33(5.7 \%)^{\mathrm{b}}$ & $23(5.7 \%)^{b}$ \\
\hline Bicyclist & $33(1.1 \%)$ & $21(0.7 \%)$ & $12(0.8 \%)$ & $5(0.9 \%)$ & $3(0.7 \%)$ \\
\hline Pedestrian-struck & $90(2.9 \%)$ & $114(4.1 \%)$ & $40(2.8 \%)$ & $20(3.4 \%)$ & $12(3.0 \%)$ \\
\hline Fall & $177(5.7 \%)$ & $144(5.1 \%)$ & $70(4.8 \%)$ & $25(4.3 \%)$ & $19(4.7 \%)$ \\
\hline Stab-wound & $402(13.0 \%)$ & $350(12.5 \%)$ & $164(11.4 \%)$ & $69(11.9 \%)$ & $34(8.5 \%)$ \\
\hline Gunshot wound & $1376(44.5 \%)$ & $1233(43.9 \%)$ & $648(44.9 \%)$ & $263(45.3 \%)$ & $182(45.4 \%)$ \\
\hline Suicide & $169(5.5 \%)$ & $143(5.1 \%)$ & $76(5.3 \%)$ & $21(3.6 \%)$ & $26(6.5 \%)$ \\
\hline \multicolumn{6}{|l|}{ Injuries, $n(\%)$} \\
\hline TBI & $309(10.0 \%)$ & $317(11.3 \%)$ & $171(11.8 \%)$ & $70(12.1 \%)$ & $43(10.7 \%)$ \\
\hline Spine & $572(18.5 \%)$ & $483(17.2 \%)$ & $228(15.8 \%)$ & $93(16.0 \%)$ & $95(23.7 \%)$ \\
\hline Heart & $3(0.1 \%)$ & $5(0.2 \%)$ & $7(0.5 \%)^{\mathrm{b}}$ & $0(0.0 \%)$ & $1(0.2 \%)$ \\
\hline Lung & $40(1.3 \%)$ & $30(1.1 \%)$ & $29(2.0 \%)$ & $9(1.6 \%)$ & $8(2.0 \%)$ \\
\hline Rib & $182(5.9 \%)$ & $248(8.8 \%)^{\mathrm{b}}$ & $126(8.7 \%)^{\mathrm{b}}$ & $49(8.4 \%)$ & $48(12.0 \%)^{b}$ \\
\hline Pelvis & $590(19.1 \%)$ & $511(18.2 \%)$ & $229(15.9 \%)$ & $111(19.1 \%)$ & $75(18.7 \%)$ \\
\hline Upper extremity & $389(12.6 \%)$ & $367(13.1 \%)$ & $214(14.8 \%)$ & $95(16.4 \%)$ & $57(14.2 \%)$ \\
\hline Lower extremity & $386(12.5 \%)$ & $414(14.7 \%)$ & $250(17.3 \%)^{\mathrm{b}}$ & $107(18.4 \%)^{\mathrm{b}}$ & $81(20.2 \%)^{b}$ \\
\hline Stomach & $284(9.2 \%)$ & $227(8.1 \%)$ & $109(7.5 \%)$ & $49(8.4 \%)$ & $32(8.0 \%)$ \\
\hline Small Intestine & $1278(41.3 \%)$ & $1126(40.1 \%)$ & $593(41.1 \%)$ & $224(38.6 \%)$ & $170(42.4 \%)$ \\
\hline Colorectal & $1080(34.9 \%)$ & $972(34.6 \%)$ & $507(35.1 \%)$ & $198(34.1 \%)$ & $129(32.2 \%)$ \\
\hline Pancreas & $85(2.7 \%)$ & $76(2.7 \%)$ & $43(3.0 \%)$ & $23(4.0 \%)$ & $13(3.2 \%)$ \\
\hline Liver & $595(19.2 \%)$ & $496(17.7 \%)$ & $259(17.9 \%)$ & $105(18.1 \%)$ & $67(16.7 \%)$ \\
\hline Spleen & $521(16.8 \%)$ & $485(17.3 \%)$ & $242(16.8 \%)$ & $106(18.3 \%)$ & $78(19.5 \%)$ \\
\hline Kidney & $294(9.5 \%)$ & $276(9.8 \%)$ & $142(9.8 \%)$ & $57(9.8 \%)$ & $44(11.0 \%)$ \\
\hline Burn & $1(0.0 \%)$ & $1(0.0 \%)$ & $2(0.1 \%)$ & $3(0.5 \%)^{\mathrm{b}}$ & $0(0.0 \%)$ \\
\hline
\end{tabular}

MVC motor vehicle collision, $M C C$ motorcycle collision, TBI traumatic brain injury

${ }^{\text {a}}$ Reference group

${ }^{\text {b}}$ Statistically significant

$(\mathrm{OR}=2.20$, CI 1.55-3.14, $p<0.001)$, and morbidly obese $(\mathrm{OR}=2.42$, CI 1.67-3.51, $p<0.001)$. The adjusted likelihood of mortality increased only in morbidly obese patients $(\mathrm{OR}=2.60$, CI 1.78-3.80, $p<0.001)$ (Table 5).

\section{Discussion}

The rising prevalence of obesity in the United States has drastically increased the likelihood that a significant portion of the trauma population will be comprised of individuals with higher BMI levels [1]. As a result, many studies have been conducted to investigate the impact of obesity on outcomes in trauma [8-26], however, its impact in trauma patients undergoing laparotomy continues to remain unclear [31-33]. Using seven years of data derived from the TQIP database, we found the likelihood of mortality in morbidly obese trauma patients to increase by 2.6 times. Additionally, we found the likelihood of PPCs such as VAP, pneumonia, and ARDS to increase as BMI increased.

The association between obesity and mortality after laparotomy has varied in the literature. A single-center study by Livingston et al. which examined about 1300 trauma patients undergoing trauma laparotomy found there was no difference in the rate of mortality regardless of BMI level [31]. In another single-center study, Haricharan et al. similarly found BMI did not contribute to the likelihood of mortality in trauma patients undergoing DCL [32]. In contrast, using a large national database with over eight thousand patients, we observed the likelihood of mortality to increase when $\mathrm{BMI} \geq 40 \mathrm{~kg} / \mathrm{m}^{2}$. Consistent with our study, a single-center study consisting of 104 trauma patients undergoing DCL by Duchesne et al. reported the likelihood of mortality to increase by nearly two-fold when $\mathrm{BMI}>40 \mathrm{~kg} / \mathrm{m}^{2}$ [33], 
Table 3 Outcomes of adult trauma patients undergoing trauma laparotomy stratified by body mass index

\begin{tabular}{|c|c|c|c|c|c|}
\hline Outcome & $\operatorname{Normal}^{\mathrm{a}}(n=3095)$ & Overweight $(n=2810)$ & Obese $(n=1444)$ & $\begin{array}{l}\text { Severely obese } \\
(n=580)\end{array}$ & $\begin{array}{l}\text { Morbidly } \\
\text { obese } \\
(n=401)\end{array}$ \\
\hline LOS, days, median (IQR) & $8.0(8)$ & $8.0(9)^{\mathrm{b}}$ & $9.0(9)^{\mathrm{b}}$ & $9.0(10)^{\mathrm{b}}$ & $10.0(14)^{b}$ \\
\hline ICU, days, median (IQR) & $3.0(4)$ & $4.0(5)^{\mathrm{b}}$ & $4.0(6)^{\mathrm{b}}$ & $5.0(7)^{\mathrm{b}}$ & $5.0(10)^{\mathrm{b}}$ \\
\hline Vent, days, median (IQR) & $2.0(3)$ & $3.0(4)$ & $3.0(4)^{\mathrm{b}}$ & $3.0(6)^{b}$ & $4.0(9)^{\mathrm{b}}$ \\
\hline \multicolumn{6}{|l|}{ Complications, $n(\%)$} \\
\hline Myocardial infarction & $4(0.1 \%)$ & $5(0.2 \%)$ & $6(0.4 \%)$ & $2(0.3 \%)$ & $2(0.5 \%)$ \\
\hline CVA & $5(0.2 \%)$ & $11(0.4 \%)$ & $13(0.9 \%)^{\mathrm{b}}$ & $4(0.7 \%)$ & $3(0.7 \%)$ \\
\hline Pneumonia & $100(3.2 \%)$ & $138(4.9 \%)^{\mathrm{b}}$ & $68(4.7 \%)$ & $41(7.1 \%)^{b}$ & $34(8.5 \%)^{b}$ \\
\hline VAP & $5(0.2 \%)$ & $7(0.2 \%)$ & $8(0.6 \%)$ & $2(0.3 \%)$ & $0(0.0 \%)$ \\
\hline Unplanned intubation & $52(1.7 \%)$ & $52(1.9 \%)$ & $27(1.9 \%)$ & $18(2.8 \%)$ & $13(3.2 \%)$ \\
\hline ARDS & $31(1.0 \%)$ & $42(1.5 \%)$ & $23(1.6 \%)$ & $11(1.9 \%)$ & $21(5.2 \%)^{\mathrm{b}}$ \\
\hline Acute kidney injury & $41(1.3 \%)$ & $72(2.6 \%)^{b}$ & $49(3.4 \%)^{\mathrm{b}}$ & $36(6.2 \%)^{b}$ & $33(8.2 \%)^{\mathrm{b}}$ \\
\hline Deep venous thrombosis & $56(1.8 \%)$ & $102(3.6 \%)^{\mathrm{b}}$ & $52(3.6 \%)^{\mathrm{b}}$ & $29(5.0 \%)^{\mathrm{b}}$ & $26(6.5 \%)^{b}$ \\
\hline Pulmonary embolism & $27(0.9 \%)$ & $44(1.6 \%)$ & $32(2.2 \%)^{\mathrm{b}}$ & $15(2.6 \%)^{\mathrm{b}}$ & $15(3.7 \%)^{\mathrm{b}}$ \\
\hline Decubitus ulcer & $20(0.6 \%)$ & $22(0.8 \%)$ & $17(1.2 \%)$ & $11(1.9 \%)^{b}$ & $10(2.5 \%)^{\mathrm{b}}$ \\
\hline Unplanned return to OR & $123(4.0 \%)$ & $128(4.6 \%)$ & $75(5.2 \%)$ & $43(7.4 \%)^{b}$ & $33(8.2 \%)^{\mathrm{b}}$ \\
\hline Unplanned ICU & $82(2.6 \%)$ & $71(2.5 \%)$ & $40(2.8 \%)$ & $20(3.4 \%)$ & $17(4.2 \%)$ \\
\hline Superficial infection & $68(2.2 \%)$ & $50(1.8 \%)$ & $35(2.4 \%)$ & $17(2.9 \%)$ & $18(4.5 \%)^{\mathrm{b}}$ \\
\hline Deep site infection & $54(1.7 \%)$ & $73(2.6 \%)$ & $42(2.9 \%)$ & $13(2.2 \%)$ & $9(2.2 \%)$ \\
\hline Urinary tract infection & $83(2.7 \%)$ & $71(2.5 \%)$ & $63(4.4 \%)^{\mathrm{b}}$ & $16(2.8 \%)$ & $26(6.5 \%)^{b}$ \\
\hline Organ space infection & $85(2.7 \%)$ & $72(2.6 \%)$ & $58(4.0 \%)$ & $14(2.4 \%)$ & $17(4.2 \%)$ \\
\hline CRBSI & $5(0.2 \%)$ & $9(0.3 \%)$ & $5(0.3 \%)$ & $5(0.9 \%)$ & $5(1.2 \%)^{b}$ \\
\hline Severe sepsis & $44(1.4 \%)$ & $54(1.9 \%)$ & $42(2.9 \%)^{b}$ & $17(2.9 \%)$ & $20(5.0 \%)^{\mathrm{b}}$ \\
\hline Mortality, $n(\%)$ & $158(5.1 \%)$ & $167(5.9 \%)$ & $87(6.0 \%)$ & $46(7.9 \%)$ & $53(13.2 \%)^{b}$ \\
\hline
\end{tabular}

$L O S$ length of stay, $I Q R$ interquartile range, $I C U$ intensive care unit, Vent ventilator, $C V A$ cerebrovascular accident, VAP ventilator-associated pneumonia, $A R D S$ acute respiratory distress syndrome, $O R$ operating room, $C R B S I$ catheter-related bloodstream infection

${ }^{\text {a }}$ Reference group

${ }^{\mathrm{b}}$ Statistically significant

Table 4 Adjusted odds ratio for pneumonia, VAP, and ARDS in adult trauma patients undergoing trauma laparotomy

\begin{tabular}{llllr}
\hline Pneumonia & & OR & CI & $\boldsymbol{p}$ value \\
\hline Body mass index* & Overweight & 1.40 & $1.07-1.84$ & 0.013 \\
& Obese & 1.36 & $0.98-1.89$ & 0.063 \\
& Severely obese & 2.25 & $1.52-3.31$ & $<0.001$ \\
& Morbidly obese & 2.12 & $1.39-3.24$ & 0.001 \\
Ventilator Associated Pneumonia & & OR & CI & $\boldsymbol{p}$ value \\
Body mass index* & Overweight & 1.37 & $0.43-4.38$ & 0.594 \\
& Obese & 3.17 & $1.01-9.97$ & 0.048 \\
& Severely obese & 2.00 & $0.36-11.0$ & 0.425 \\
& Morbidly obese & 0.00 & $0.00-0.00$ & 0.993 \\
Acute Respiratory Distress Syndrome & & OR & CI & $\boldsymbol{p}$ value \\
Body mass index* & Overweight & 1.38 & $0.86-2.21$ & 0.187 \\
& Obese & 1.41 & $0.80-2.46$ & 0.232 \\
& Severely obese & 1.85 & $0.92-3.73$ & 0.087 \\
& Morbidly obese & 4.85 & $2.72-8.65$ & $<0.001$ \\
\hline
\end{tabular}

Controlled for age $\geq 65$, injury severity score $\geq 25$, chronic obstructive pulmonary disease, smoking, rib injury, lung injury, transfusion of $\geq 1$ units of packed red blood cells within $24 \mathrm{~h}$

*Reference group included normal BMI 
Table 5 Adjusted odds ratio for PPCs and mortality in adult trauma patients undergoing trauma laparotomy

\begin{tabular}{lllll}
\hline $\begin{array}{l}\text { Postoperative pulmonary compli- } \\
\text { cations }^{\text {a }}\end{array}$ & OR & CI & $p$ value \\
\hline Body mass index $^{*}$ & Overweight & 1.37 & $1.07-1.74$ & 0.012 \\
& Obese & 1.44 & $1.08-1.92$ & 0.014 \\
& Severely obese & 2.20 & $1.55-3.14$ & $<0.001$ \\
& Morbidly obese & 2.42 & $1.67-3.51$ & $<0.001$ \\
Mortality $^{b}$ & & OR & CI & $\boldsymbol{p}$ value \\
Body mass index $^{*}$ & Overweight & 1.02 & $0.80-1.30$ & 0.860 \\
& Obese & 1.03 & $0.77-1.39$ & 0.842 \\
& Severely obese & 1.46 & $0.99-2.15$ & 0.050 \\
& Morbidly obese & 2.60 & $1.78-3.80$ & $<0.001$ \\
\hline
\end{tabular}

${ }^{a}$ Controlled for age $\geq 65$, injury severity score $\geq 25$, chronic obstructive pulmonary disease, smoking, rib injury, lung injury, transfusion of $\geq 1$ units of packed red blood cells within $24 \mathrm{~h}$

${ }^{\mathrm{b}}$ Controlled for age $\geq 65$, injury severity score $\geq 25$, AIS head severe, PPCs, CHF, diabetes mellitus, hypertension, unplanned return to the operating room

*Reference group included normal BMI

suggesting obesity may be a predictive factor for mortality after trauma laparotomy at higher BMI levels. It is possible patients with higher BMI levels have a more complex and difficult post-injury hospital course, which then results in a higher likelihood for mortality. This is reflected in our patient population which had a higher LOS, ICU LOS, and median ventilator days as BMI increased. The morbidly obese also had higher rates of unplanned return to the operating room, decubitus ulcers, and infections such as superficial infections, catheter-related bloodstream infections and severe sepsis. This higher rate of complications likely adds to their higher likelihood of mortality.

The association between obesity and the development of PPCs after laparotomy is not definitively known. Several single-center studies have attempted to assess this relationship. One study found the likelihood of pneumonia and ARDS to be no different among obese trauma patients undergoing trauma laparotomy relative to normal BMI patients [31]. Another study found the likelihood of pneumonia to be higher in overweight and obese trauma patients undergoing DCL [32]. A final study found the likelihood of ARDS to be no different in obese trauma patients undergoing DCL [33]. In our study, the likelihood of PPCs was found to increase as BMI increased. One explanation for this discrepancy is the difference in powering of these studies as our study had nearly 8 times the patients of the aforementioned studies. It is well known that obesity may cause decreased chest wall compliance, decreased lung volumes, increased oxygen consumption, increased respiratory rate, mild hypoxemia, and increased airway resistance, all of which can predispose obese individuals to obstructive sleep apnea (OSA) and obesity hypoventilation syndrome [38-41]. These changes in obese individuals also present with difficulties in airway management given the challenges to oxygenation and ventilation [39]. This is further exemplified in our data where morbidly obese patients had an increased rate of unplanned intubation as well. Interventions that have proven useful in obese patients during the postoperative phase include use of continuous positive airway pressure and noninvasive ventilation [42-44] as well as incentive spirometry, targeted pulmonary toilet, respiratory physiotherapy, and early mobilization $[42,45,46]$. These interventions should be implemented for all obese trauma patients undergoing laparotomy.

As a large retrospective database study, there are inherent limitations to this work including coding errors and reporting bias. Additionally, given the retrospective nature of our work, our findings cannot be interpreted as causation and serve primarily to establish correlation and warrant further exploration. Furthermore, the use of BMI as a surrogate for estimating body fat and thus obesity may be an important limiting factor as well. Although BMI is widely accepted and is the most readily available tool for stratifying patients by weight, it is truly excess body fat rather than the excess weight that correlates with ill-health. Given that BMI is calculated based on just height and weight, it also fails to account for other factors like age, sex, muscularity, and ethnicity that play a role in determining a patient's body fat. The unstandardized fashion in which height and weight are collected across the country also serves as a limiting factor. While many trauma centers directly measure these values, other trauma centers rely on self-reported values or estimates. Furthermore, the diagnosis of pneumonia (especially non-ventilator related) is often made clinically rather than with quantitative cultures, resulting in a lower sensitivity and specificity. As a result, the true population of patients with pneumonia may not be fully captured. In addition, the TQIP database is limited to the index hospitalization thus long term and functional outcomes are absent. Additionally, pertinent data points unavailable within TQIP include whether the patients were American Society of Anesthesiologists class II or greater or had OSA, both of which have been identified as risk factors for the development of PPCs $[30,47]$. There is also no information pertaining to how the laparotomy was performed within TQIP.

\section{Conclusion}

In this study, an association was found for both PPCs and mortality in relation to increased BMI. The likelihood for PPCs is greater starting with patients of BMI $\geq 25 \mathrm{~kg} / \mathrm{m}^{2}$ and increases with each higher category of BMI, culminating with a nearly 2.4 times increased likelihood for PPCs in morbidly obese patients. The likelihood for mortality 
increases in patients with $\mathrm{BMI} \geq 40 \mathrm{~kg} / \mathrm{m}^{2}$. This suggests obesity should be accounted for in risk prediction models of trauma patients undergoing trauma laparotomy. However, prior to implementation, future prospective studies should confirm these findings.

Author contributions Dr. Covarrubias and Drs. Nahmias and Grigorian were involved in the development of the study design as well as completion of the manuscript. Dr. Grigorian compiled the necessary study statistics. All authors were involved in the analysis of data and provided critical revisions to the manuscript.

Funding This research did not receive any specific grant from funding agencies in the public, commercial, or not-for-profit sectors.

\section{Compliance with ethical standards}

Conflict of interest The authors report no conflicts of interest, financial or otherwise.

Ethical approval This retrospective study involved humans but since a national database was used with de-identified patients, the risk was minimal to participants.

Informed consent No consent was required.

\section{References}

1. Hales CM, Carroll MD, Fryar CD, Ogden CL. Prevalence of obesity among adults and youth: United States, 2015-2016. NCHS data brief, no 288. Hyattsville, MD: National Center for Health Statistics. 2017.

2. Wee CC, Huskey KW, Ngo LH, et al. Obesity, race, and risk for death or functional decline among Medicare beneficiaries: a cohort study. Ann Intern Med. 2011;154:645-55.

3. Rahmouni K, Correia ML, Haynes WG, et al. Obesity-associated hypertension: new insights into mechanisms. Hypertension. 2005;45:9-14.

4. Chan JM, Rimm EB, Colditz GA, et al. Obesity, fat distribution, and weight gain as risk factors for clinical diabetes in men. Diabetes Care. 1994;17:961-9.

5. Schwartz AR, Patil SP, Laffan AM, et al. Obesity and obstructive sleep apnea: pathogenic mechanisms and therapeutic approaches. Proc Am Thorac Soc. 2008;5:185-92.

6. Olson AL, Zwillich C. The obesity hypoventilation syndrome. Am J Med. 2005; 118:948-56.

7. Hsu CY, McCulloch CE, Iribarren $\mathrm{C}$, et al. Body mass index and risk for end-stage renal disease. Ann Intern Med. 2006;144:21-8.

8. Choban P, Weireter LJ, Maynes C. Obesity and increased mortality in blunt trauma. J Trauma. 1991;31:1253-7.

9. Brown CV, Neville AL, Rhee PR, et al. The impact of obesity on the outcomes of 1153 critically injured blunt trauma patients. J Trauma. 2005;59:1048-51.

10. Ryb GE, Dischinger PC. Injury severity and outcomes of overweight and obese patients after vehicular trauma: a Crash Injury Research and Engineering Network (CIREN) study. J Trauma. 2008;64:406-11.

11. Mock CN, Grossman DC, Kaufman RP, et al. The relationship between body weight and risk of death and serious injury in motor vehicle crashes. Accid Anal Prev. 2002;34:221-8.
12. Bochicchio GV, Joshi M, Bochicchio K, et al. Impact of obesity in the critically ill trauma patient: a prospective study. J Am Coll Surg. 2006;203:533-8.

13. Arbabi S, Wahl WL, Hemmila MR, et al. The cushion effect. J Trauma. 2003;54:1090-3.

14. Nelson J, Billeter AT, Seifert B, et al. Obese trauma patients are at increased risk of early hypovolemic shock: a retrospective cohort analysis of 1084 severely injured patients. Crit Care Med. 2012;16(3):R77.

15. Hoffmann M, Lefering R, Gruber-Rathmann M, et al. The impact of BMI on polytrauma outcome. Injury. 2012;43:184-8.

16. Newell MA, Bard MR, Goettler CE, et al. Body mass index and outcomes in critically injured blunt trauma patients: weighing the impact. J Am Coll Surg. 2007;204:1056-61.

17. Duane TM, Dechert T, Aboutanos MB, et al. Obesity and outcomes after blunt trauma. J Trauma. 2006;61:1218-21.

18. Belzberg H, Wo CC, Demetriades D, Shoemaker WC. Effects of age and obesity on homodynamic, tissue oxygenation, and outcome after trauma. J Trauma. 2007;62:1192-200.

19. Alban RF, Lyass S, Margulies DR, Shabot MM. Obesity does not affect mortality after trauma. Am Surg. 2006;72:966-9.

20. Evans DC, Stawicki SPA, Tracy Davido H, Eiferman D. Obesity in trauma patients: correlations of body mass index with outcomes, injury patterns and complications. Am Surg. 2011;77(8):1003-8.

21. Ciesla DJ, Moore EE, Johnson JL, et al. Obesity increases risk of organ failure after severe trauma. J Am Coll Surg. 2006;203:539-45

22. Dossett LA, Heffernan D, Lightfoot M, et al. Obesity and pulmonary complications in critically injured adults. Chest. 2008;134(974-80): 17.

23. Winfield RD, Delano MJ, Lottenberg L, et al. Traditional resuscitative practices fail to resolve metabolic acidosis in morbidly obese patients after severe blunt trauma. J Trauma. 2010;68:317-30.

24. Liu T, Chen J, Bai X, et al. The effect of obesity on outcomes in trauma: a meta-analysis. Inj Int J Care Inj. 2013;44:1145-52.

25. Ditello M, Pandit V, Rhee P, et al. Morbid obesity predisposes trauma patients to worse outcomes: a national trauma data bank analysis. J Trauma Acute Care Surg. 2014;76(1):176-9.

26. Glance LG, Li Y, Osler TM, et al. Impact of obesity on mortality and complications in trauma patients. Ann Surg. 2014;259(3):576-81.

27. Sachdev G, Napolitano LM. Postoperative pulmonary complications: pneumonia and acute respiratory failure. Surg Clin North Am. 2012;92(2):321-44.

28. Gundel O, Gundersen SK, Dahl RM, et al. Timing of surgical site infection and pulmonary complications after laparotomy. Int J Surg. 2018;52:56-60.

29. Bamgbade OA, Rutter TW, Nafiu OO, et al. Postoperative complications in obese and nonobese patients. World J Surg. 2007;31:556-60.

30. Qaseem A, Snow V, Fitterman N, et al. Risk assessment for and strategies to reduce perioperative pulmonary complications for patients undergoing noncardiothoracic surgery: a guideline from the American College of Physicians. Ann Intern Med. 2006; $144: 575-80$.

31. Livingston DH, Lavery RF, N'Kanza A, et al. Obesity does not increase morbidity and mortality after laparotomy for trauma. Am Surg. 2013;79(3):247-52.

32. Haricharan RN, Dooley AC, Weinberg JA, et al. Body mass index affects time to definitive closure after damage control surgery. $\mathrm{J}$ Trauma. 2009;66(6):1683-7.

33. Duchesne JC, Schmieg RE, Simmons JD, et al. Impact of obesity in damage control laparotomy patients. J Trauma. 2009;67(1):108-12.

34. World Health Organization. BMI Classification. WHO online. Accessed 19 April 2019. 
35. MacLeod J, Lynn M, McKenney MG, Jeroukhimov I, Cohn SM. Predictors of mortality in trauma patients. Am Surg. 2004;70(9):805-10.

36. Jelodar S, Jafari P, Yadollahi M, et al. Potential risk factors of death in multiple trauma patients. Emergency. 2014;2(4):170-3.

37. Wardle TD. Co-morbid factors in trauma patients. Br Med Bull. 1999;55(4):744-56.

38. Littleton SW. Impact of obesity on respiratory function. Respirology. 2012;17:43-9.

39. Murphy C, Wong DT. Airway management and oxygenation in obese patients. Can J Anesth. 2013;60:929-45.

40. Benumof JL. Obesity, sleep apnea, the airway and anesthesia. Curr Opin Anaesthesiol. 2004;17:21-30.

41. Raveendran R, Wong J, Singh M, et al. Obesity hypoventilation syndrome, sleep apnea, overlap syndrome: perioperative management to prevent complications. Curr Opin Anaesthesiol. 2017;30(1):146-55
42. Hodgson LE, Murphy PB, Hart N. Respiratory management of the obese patient undergoing surgery. J Thorac Dis. 2015;7(5):943-52.

43. Ferreyra G, Long Y, Ranieri VM. Respiratory complications after major surgery. Curr Opin Crit Care. 2009;15:342-8.

44. Jaber S, Chanques G, Jung B. Postoperative noninvasive ventilation. Anesthesiology. 2010;112:453-61.

45. Torrington KG, Sorenson DE, Sherwood LM. Postoperative chest percussion with postural drainage in obese patients following gastric stapling. Chest. 1984;86(6):891-5.

46. Valenza F, Vagginelli F, Tiby A, et al. Effects of the beach chair position, positive end-expiratory pressure, and pneumoperitoneum on respiratory function in morbidly obese patients during anesthesia and paralysis. Anesthesiology. 2007;107(5):725-32.

47. Kaw R, Chung F, Pasupuleti V, et al. Meta-analysis of the association between obstructive sleep apnoea and postoperative outcome. Br J Anaesth. 2012;109(6):897-906. 